\title{
Green Synthesis and Characterization of Silver Nanoparticles and Evaluation of their Antibacterial Activity using Elettaria Cardamom Seeds
}

\section{Omprakash $\mathrm{V}^{1 *}$ and Sharada $\mathrm{S}^{2}$}

${ }^{1} P G$ Nanotechnology, Department of Chemical Engineering JNTUA College of Engineering, Anantapuramu- 515002, Andhra Pradesh, India ${ }^{2}$ Assistant Professor, Department of Chemical Engineering, JNTUA College of Engineering, Anantapuramu- 515002, Andhra Pradesh, India

\begin{abstract}
In present we have been producing metallic nanoparticles with toxic and harmful chemicals which are more dangerous to environment. Therefore there is a need to develop environment friendly synthesis techniques without using toxic chemicals. In this work a simple and green/eco-friendly/chemical free biosynthesis of silver nanoparticles using C seed extract as reducing agents was prepared. Nanoparticles were characterized by UV-vis absorbance spectroscopy, XRD and SEM measurements. The metal ions reduction occurs very rapidly, and the reduction of Ag ions will be completed within 4 hours. The synthesized silver Nanoparticle distinct monodispersity as they show particle size between the ranges of 30-80 $\mathrm{nm}$. The experimental study confirmed the formation of highly crystalline nanoparticles with uniform shape. Further, the antibacterial activity against the Bacillus subtilis was also evaluated for Elettaria cardamom seeds extract assisted silver nanoparticles and the later found to exhibit significant activity.
\end{abstract}

Keywords: Elettaria cardamom seed; Nanoparticle; UV-Vis spectrophotometer; SEM; XRD

\section{Introduction}

\section{Nanotechnology}

Nanotechnology ("nanotech") is the manipulation of matter on an atomic, molecular, and nano scale. The earliest, widespread description of nanotechnology [1,2] referred to the particular technological goal of precisely manipulating atoms and molecules for fabrication of macro scale products, also now referred to as molecular nanotechnology. A more generalized description of nanotechnology was subsequently established by the National Nanotechnology Initiative, which defines nanotechnology as the manipulation of matter with at least one dimension sized from 1 to 100 nanometers. This definition reflects the fact that quantum mechanical effects are important at this quantum-realm scale, and so the definition shifted from a particular technological goal to a research category inclusive of all types of research and technologies that deal with the special properties of matter that occur below the given size threshold. Because of the variety of potential applications (including industrial and military), governments have invested billions of dollars in nanotechnology research. Through its National Nanotechnology Initiative, the USA has invested 3.7 billion dollars. The European Union has invested 1.2 billion and Japan 750 million dollars [3]. Nanotechnology as defined by size is naturally very broad, including fields of science as diverse as surface science, organic chemistry, molecular biology, semiconductor physics, micro fabrication, etc. [4]. The associated research and applications are equally diverse, ranging from extensions of conventional device physics to completely new approaches based upon molecular self-assembly, from developing new materials with dimensions on the nanoscale to direct control of matter on the atomic scale (Figure 1).

Scientists currently debate on the future inventions of nanotechnology. Nanotechnology may be able to create many new materials and devices with a wide range of applications, such as in medicine, electronics, biomaterials and energy production. On the other hand, nanotechnology raises many of the same issues as any new technology, including concerns about the toxicity and environmental impact of nanomaterials [5]. These concerns have led to a debate among advocacy groups and governments on whether special regulation of nanotechnology is warranted.

Although there are some reports on the synthesis of AgNPs from fruits, to the best of our knowledge till date there is no report available on Elettaria cardamom seeds extract for the reduction of metal salts to get nanoparticles. As part of our contributions to the growing interest of biomediated synthesis of SNPs, we report for the first time an inexpensive one pot synthesis of AgNPs by green route at room temperature, stabilized in situ using Elettaria cardamom seed extracts.

Synthesis and characterization of silver nanoparticles and evaluation of their antibacterial activity

Nanotechnology deals with the materials at nanoscale and the nanoparticles are being considered as its fundamental building blocks. The nanoparticles exhibits completely new and improved properties as compared to their bulk counterpart due to variation in specific characteristics such as size, distribution and of the particles which give rise to larger surface area to volume ratio [6]. Metal nanoparticles have tremendous applications in the field of science and technology due to their unique electronic, mechanical, optical and magnetic properties [7]. In recent years the silver nanoparticles have greatly focused the researcher's attention because of their important application as antimicrobial, catalytic, textile fabrics and plastics to eliminate micro-organisms. The silver nanoparticles are specifically used as antibacterial/antifungal agents in biotechnology and bioengineering. They can be used for targeted drug delivery which is more effective and

*Corresponding author: Omprakash V, PG Nanotechnology, Department of Chemical Engineering JNTUA College of Engineering Anantapur, Anantapuramu- 515002, Andhra Pradesh, India, Tel: 08554-272083; E-mail: omprakashindian89@gmail.com

Received Decmber 29, 2014; Accepted February 25, 2015; Published March 15,2015

Citation: Omprakash V, Sharada S (2015) Green Synthesis and Characterization of Silver Nanoparticles and Evaluation of their Antibacterial Activity using Elettaria Cardamom Seeds. J Nanomed Nanotechnol 6: 266. doi:10.4172/21577439.1000266

Copyright: @ 2015 Omprakash V, et al. This is an open-access article distributed under the terms of the Creative Commons Attribution License, which permits unrestricted use, distribution, and reproduction in any medium, provided the original author and source are credited. 


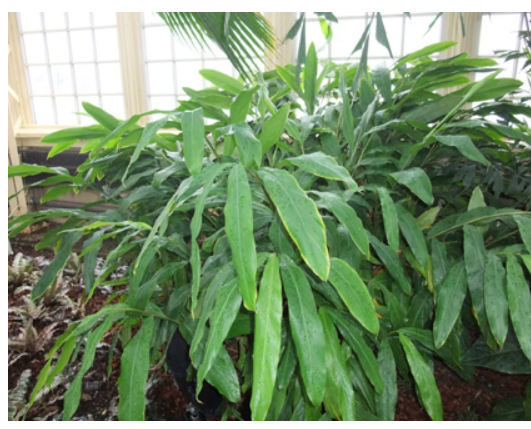

Figure 1: Elettaria Cardamom plant.

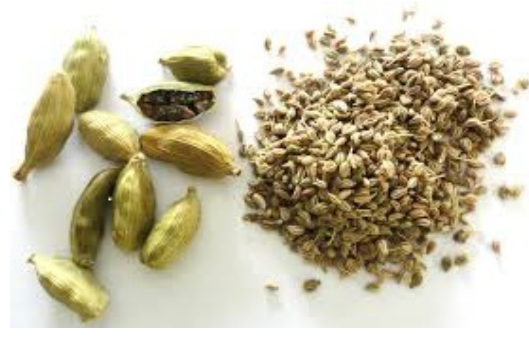

Figure 2: Dry seed of Elettaria cardamom.

having fewer side effects as compared to its bulk counterpart. The silver nanoparticles can be synthesized by number of physical and chemical techniques [8-11]. Unfortunately, many of these techniques are either expensive or involve the use of hazardous chemicals. Therefore there is a growing need to develop environment friendly synthesis techniques without using toxic chemicals. Bio-synthesis of nanoparticles is a fast growing research in nanotechnology.

Nowadays, plant extract has been used as reducing and capping agent for the synthesis of nanoparticles. The use of plant extract is more advantageous because it does not require elaborate processes such as intracellular synthesis and multiple purification steps or the maintenance of microbial cell culture [12]. The biosynthesis of silver nanoparticles using Azadirachta indica [12], Cissus quadrangularis [12], Catharanthus roseus [13], Cinnamomum camphora [14], Phoma glomerata [15], Nicotiana tobaccum [15] and Elettaria cardamom [16] etc. have beenreported in literature.

\section{Materials and Methods}

\section{Preparation of seed broth}

Fresh Elettaria cardamom seeds (Figure 2) were purchased from local market and are thoroughly washed with distilled water and dried at room temperature. The seeds were grinded to fine powder using modern pestle. About $20 \mathrm{~g}$ of freshly prepared dry seed powder was suspended in $150 \mathrm{ml}$ of distilled water and boiled at $75^{\circ} \mathrm{C}$ temperature for 1.30 hour. Then filtered the solution through whatmann filter paper No.1 and the solution obtained was used as extract for further experimental work.

\section{Synthesis of silver Nanoparticle}

The silver nitrate $\left(\mathrm{AgNO}_{3}\right)$ was used as a precursor in the silver nanoparticle synthesis process. About $10 \mathrm{ml}$ of Elettariacardamom seed extract was added to $40 \mathrm{ml}$ of different concentration of $\mathrm{AgNO}_{3}$
$(0.14,0.16,0.18,0.20$ and $0.22 \mathrm{gm})$ aqueous solution in conical flask. The mixture was boiled at $75^{\circ} \mathrm{C}$ for 30 minutes, while heating the color of solution was changed from pale brown to dark brown. The reduction of $\mathrm{Ag}+$ ions to $\mathrm{Ag} 0$ was monitored by measuring the UV-Vis spectrum of various concentration of reaction mixture (silver nitrate solution+ seed extract) (Figure 3).

\section{Characterization studies}

The reduction of silver metal ions to silver Nanoparticle was preliminary analyzed by using UV-visible Spectrophotometer (Perkin-Elmer) of wavelength about $360-700 \mathrm{~nm}$ at regular time intervals. After that, the solution mixture (Seed extract and Silver nitrate) was centrifuged at $15,000 \mathrm{rpm}$ for $20 \mathrm{~min}$ and repeated the centrifugation process for 3 to 4 times and filtered the resulting solution through whatman No.1 filter paper and dry the pellet in hot air oven. Furthermore, the dried particles were characterized by (SEM) were performed using a Philips model CM 200 instrument to study the morphological nature of the nanoparticle. The X-ray diffraction patterns were recorded on an X-ray diffractometer. The XRD pattern proposes the crystalline nature of the Ag Nanoparticle synthesized from aqueous extracellular Elettaria cardamomum seed extract.

\section{Results and Discussion}

\section{UV-Visible spectroscopy}

UV-Visible spectroscopy is an important technique to determine the formation and stability of metal Nanoparticle in aqueous solution. The reaction mixture changes the color by adding various concentrations of metal ions. These color changes arise because of the excitation of surface Plasmon vibrations in the silver nanoparticle. It shows yellowish to dark brown in color (Figure 4). The dark brown color of silver colloids accepted to surface Plasmon resonance (SPR) arising due to the group of free conduction electrons induced byan interacting electromagnetic field. The strong surface Plasmon resonance band appears at the range of 440-480 $\mathrm{nm}$ and the broadening of peak indicated that the particles are monodispersed.

\section{SEM (Scanning Electron Microscope)}

After the reduction of silver ions by the Elettaria cardamom seed extract, the solution was centrifuged at $10,000 \mathrm{rpm}$ for $15 \mathrm{~min}$. Repeat the centrifugation process to separate silver nanoparticle free from other organic compounds present in solution. The Ag Nanoparticle pellet obtained after centrifugation were redisposed in distilled water and washed for 2 or 3 times. The synthesized Nanoparticles morphology were characterized by scanning electron microscope, this

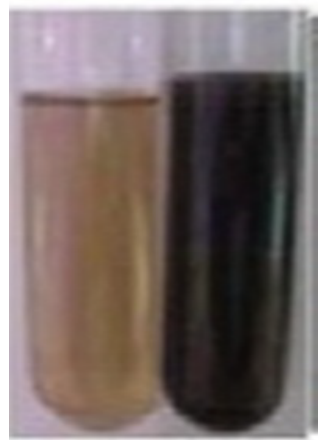

Figure 3: Color of solution was changed from pale brown to dark brown. 
Citation: Omprakash V, Sharada S (2015) Green Synthesis and Characterization of Silver Nanoparticles and Evaluation of their Antibacterial Activity using Elettaria Cardamom Seeds. J Nanomed Nanotechnol 6: 266. doi:10.4172/2157-7439.1000266

Page 3 of 4

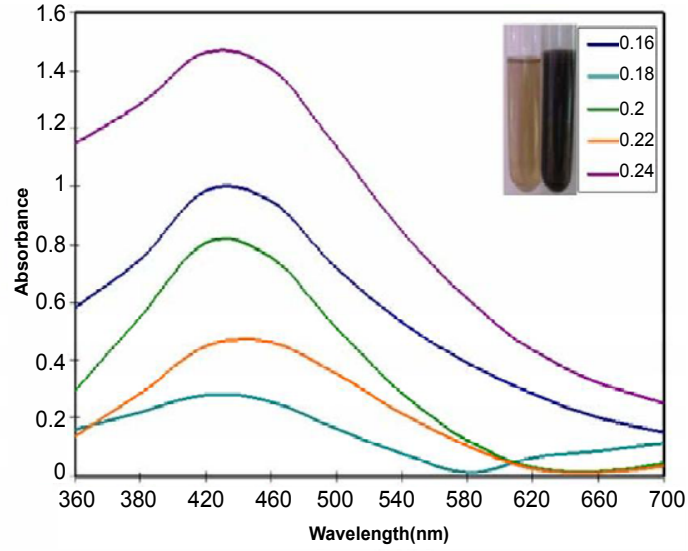

Figure 4: UV-Visible absorption spectra of biosynthesized silver Nanoparticle from E.cardamomom depicting peak at $460 \mathrm{~nm}$. The inset shows extract before (left) and after (right) exposure to silver nitrate.

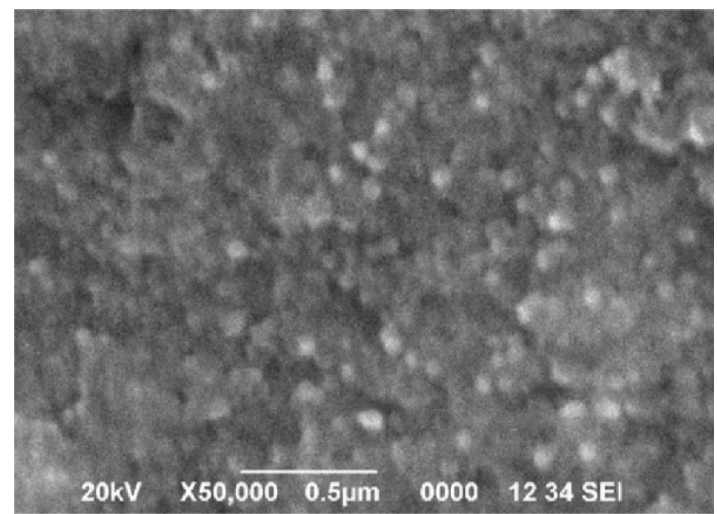

Figure 5: The SEM images of silver Nanoparticle synthesized from the $E$. cardamom seed extracts at various magnifications.

micrograph was taken using a Philips model CM 200 instrument. The silver Nanoparticle formed were predominantly spherical with uniform shape (Figure 5). It is known that the shape of metal Nanoparticle considerably change their optical and electronic properties. The SEM image exposed that the formed nanoparticle was spherical in shape formed with the size range of $40-70 \mathrm{~nm}$.

\section{X-Ray diffraction}

A representative XRD profile of the silver nanoparticle displaying the structural information and crystalline nature of the silver Nanoparticle synthesized from aqueous extracellular E. cardamom seed extract. The XRD measurements of film of the biologically synthesized silver Nanoparticle cast onto glass slides were done and examined on a Phillips PW 1830 instrument (Figure 6). The XRD pattern showed three intense peaks at $38^{\circ}, 47^{\circ}$, and $77^{\circ}$ corresponding to 111,200 and 311 planes in the whole spectrum of $2 \theta$. The average particle size of the silver Nanoparticle was identified by using the following DebyeScherer's equation (1) and it follows (Table 1).

$$
\mathrm{D}=\frac{\mathrm{k} \lambda}{(\beta \operatorname{coz} \theta)}
$$

\section{Antibacterial activity of various concentrations of $\mathrm{Ag}$ nanoparticle}

The exact mechanism of the antibacterial effect of silver ions is partially understood. Literature survey reveals that the positive charge on the $\mathrm{Ag}$ ion is crucial for its antimicrobial activity. The antibacterial activity is probably derived, through the electrostatic attraction between negative charged cell membrane of microorganism and positive charged Nanoparticles [17-20]. However, Sondi and Salopek-Sondi [21] reported that the antimicrobial activity of silver Nanoparticles on Gram-negative bacteria was dependent on the concentration of Ag Nanoparticles and was closely associated with the formation of pits in the cell wall of bacteria. The antibacterial efficacy of the biogenic silver Nanoparticles reported in the present study may be ascribed to the mechanism described above but it still remains to clarify the exact effect of the Nanoparticles on important cellular metabolism like DNA, RNA and protein synthesis (Figure 7).

\section{Effect of Ag-NPs on protein leakage from bacterial cell membranes}

It was found that Ag-NPs could enhance protein leakage by increasing the membrane permeability of $S$. aureus and E. coli cells.

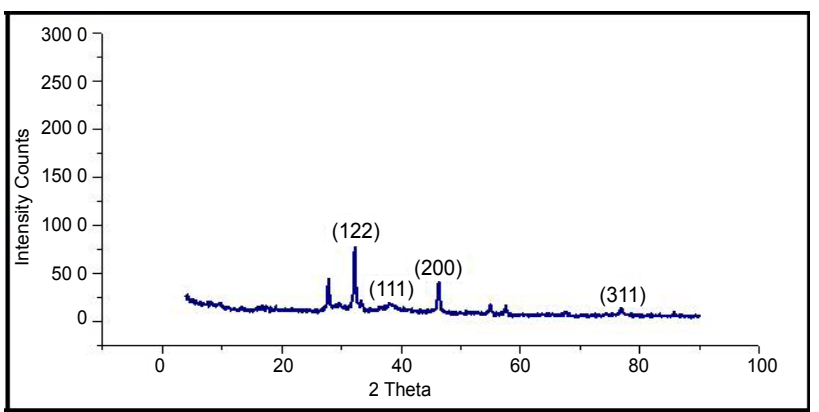

Figure 6: XRD patterns of silver Nanoparticle synthesized using $E$. cardamom seed broth.

\begin{tabular}{|c|c|c|c|c|}
\hline Lattice Planes & Peak Width & Peak Position & Crystal Size & Lattice Strain \\
\hline 111 & 0.4 & 38 & $22 \mathrm{~nm}$ & 0.051 \\
\hline 200 & 0.1 & 47 & $90.51 \mathrm{~nm}$ & 0.0010 \\
\hline 311 & 0.3 & 77 & $35 \mathrm{~nm}$ & 0.0016 \\
\hline 122 & 0.075 & 43 & $118.95 \mathrm{~nm}$ & 0.0008 \\
\hline
\end{tabular}

Table 1: Calculated values of XRD

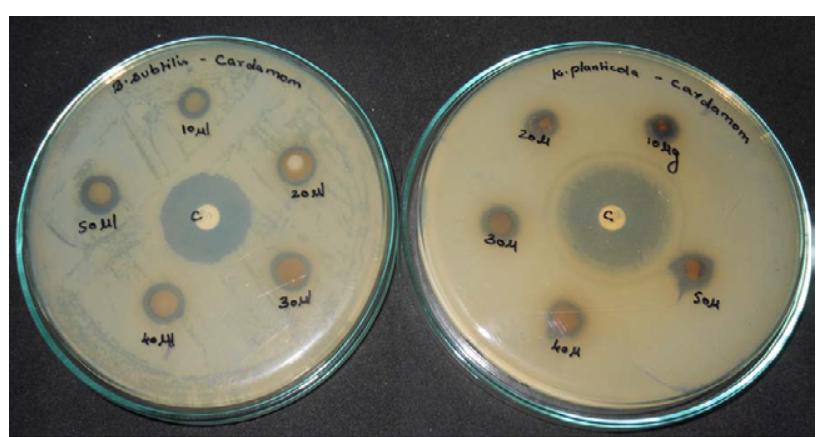

Figure 7: Antibacterial activity of various concentrations of $\mathrm{Ag}$ Nanoparticle against selective bacterial pathogens (Bacillus subtilis. Klebsiella planticola). 
Citation: Omprakash V, Sharada S (2015) Green Synthesis and Characterization of Silver Nanoparticles and Evaluation of their Antibacterial Activity using Elettaria Cardamom Seeds. J Nanomed Nanotechnol 6: 266. doi:10.4172/2157-7439.1000266

Initially, protein leakage from the membranes of $S$. aureus cells treated with Ag-NPs was almost the same as that from cells in the control group. At $6 \mathrm{~h}$ after incubation, protein leakage from cells treated with Ag-NPs considerably increased; however, there was no change in the amount of protein leakage from cells in the control group. Leakage from cells treated with Ag-NPs was significantly higher than that from cells in the control group. Furthermore, the initial protein leakage from the membranes of $E$. coli cells treated with Ag-NPs was almost the same as that from cells in the control group. At $6 \mathrm{~h}$ after incubation, protein leakage from E. coli cells treated with Ag-NPs was significantly increased compared to that from cells in the control group, indicating that AgNPs can increase membrane permeability. Notably, higher amounts of proteins leaked through the E. coli membranes compared to those through the $S$. aureus membranes, suggesting that the antibacterial sensitivity of the Gram-positive $S$. aureus was lower than that of the Gram-negative E. coli $[22,23]$. This difference was possibly attributable to the thickness of the peptidoglycan layer of $S$. aureus; an essential function of the peptidoglycan layer is to protect against antibacterial agents such as antibiotics, toxins, chemicals, and degradative enzymes. This result was consistent with the results of previous studies.

\section{Conclusion}

In the present investigation, a facile, environmentally benevolent green synthetic route is used for synthesis of silver Nanoparticle. The Phytofabrication of silver nanoparticle by using seed extract of E. cardamom without involvement of any toxic chemicals. The metal ions reduction occurs very rapidly, and the reduction of Ag ions will be completed within 4 hours. The synthesized silver Nanoparticle distinct monodispersity as they show particle size between the range of 30-80 nm. Water soluble heterocyclic compounds such as flavones were mainly responsible for the reduction and stabilization of the Nanoparticle. Assessment on the antibacterial effect of nanosized silver colloidal solution against Bacillus subtilis and Klebsiella plantcola reveals high efficacy of silver Nanoparticle as a strong antibacterial agent. The present used seeds of E.cardamomom as a source which is easily obtainable and extensively useful in biomedical application.

\section{References}

1. Drexler E (1986) Engines of Creation: The Coming Era of Nanotechnology. Doubleday.

2. Drexler KE (1992) Nanosystems: Molecular Machinery, Manufacturing, and Computatin. John Wiley \& Sons Inc, New York, NY, USA.

3. The Daily Star (2012) Apply nanotech to up Industrial, Agri output

4. Rajiv S, Santosh S, Sugandha S (2010) Nanotechnology: The Future Medicine. Journal of Cutaneous and Aesthetic Surgery 3: 32-33.

5. CristinaB, Pacheco IIB, Robbie K (2007) Nanomaterials and Nanoparticles: Sources and Toxicity. Biointerphases 2: MR17-MR172.

6. Singh A, Jain D, Upadhyay MK, Khandelwal N, Verma HN (2001) Green synthesis of silver nanoparticles using Argimonemexicana leaf extract and Evaluation of their antimicrobial activities. Digest $\mathrm{J}$ Nanomat and Biostruct 5 : 483-489.

7. Bisen DP, Sharma R, Brahme N, Tamrakar R (2009) Effect of temperature on the synthesis of CdS:Mn doped nanoparticles. Chalcogenide Lett 6: 427-431.

8. Begum NA, Mondal S, Basu S, Laskar RA, Mandal D (2009) Biogenic synthesis of $\mathrm{Au}$ and $\mathrm{Ag}$ nanoparticles using aqueous solutions of black tea leaf extracts. Colloids and Surface B Biointerfaces 71: 113-118.

9. Rastogi RP, Mehrotra BN (1998) Compendium of Indian Medicinal Plants. Central Drug Research Institute, New Delhi, India.

10. Yang WT, Li H, Gong Y, Chen WY, Gaidau C (2011) Preparation of silver nanoparticles of enhanced antibacterial effect with benzalkonium bromide. $J$ Optoelect Adv Mater 13: 661-665
11. Mukunthan KS, Elumalai EK, Trupti NP, Murti VR (2011) Catharanthusroseus: A natural source for the synthesis of silver nanoparticles. Asian pacific journal of tropical biomedicine 1: 270-274.

12. Mulongo G, Mbabazi J, Hak-Chol S (2011) Synthesis and Characterisation of Silver Nanoparticles using High Electrical Charge Density and High Viscosity Organic Polymer. Res J Chem Sci 1: 18-21.

13. Renugadevi K, Aswini V, Raji P (2012) Microwave Irradiation Assisted Synthesis of Silver Nanoparticle Using Leaf Extract of BaliospermumMontanum and Evaluation of its Antimicrobial, Anticancer Potential Activity. Asian J Pharm Clin Res 5: 283-287.

14. Ponarulselvam S, Panneerselvam C, Murugan K, Aarthi N, Kalimuthu K, et al (2012) Synthesis of silver nanoparticles using leaves of Catharanthusroseus Linn. G. Don and their antiplasmodial activities. Asian Pacific Journal of Tropical Biomedicine 2: 574-580.

15. Xin Y, Qingbiao LI, Huixuan W, Jiale H, Liqin L, et al. (2010) Green synthesis of palladium nanoparticles using broth of Cinnamomumcamphora leaf. J Nanopart Res 12: 1589-1598.

16. Birla SS, Tiwari VV, Gade AK, Ingle AP, Yadav AP, et al. (2009) Fabrication of silver nanoparticles by Phomaglomerata and its combined effect against Escherichia oli, Pseudomonas aeruginosa and Staphylococcusaureus. Lett App Microbio 48: 173-179.

17. Jobitha GDG, Annadurai G, Kannan C (2012) Green synthesis of silver nanoparticle using Elettariacardamomom and assessment of its antimicrobial activity. Inter J of Pharma Sci and Research 3: 0975-9492.

18. Raut RW, Kolekar NS, Lakkakula JR, Mendhulkar VD, Kashid SB (2010) Extracellular synthesis of silver Nanoparticle usingdried leaves of pongamia pinnata (L) Pierre. Nano-Micro Letters 2: 106-113.

19. Hamouda T, Myc A, Donovan B, Shih A, Reuter JD, et al. (2000) A nove surfactant nanoemulsion with a unique nonirritant topical antimicrobial activity against bacteria, enveloped viruses and fungi. Microbiol Res 156: 1-7.

20. Dibrov P, Dzioba J, Gosink KK, Hase CC (2002) Chemiosmotic Mechanism of Antimicrobial Activity of $\mathrm{Ag}+$ in Vibrio cholerae. Antimicrob Agents Chemother 46: $2668-2670$.

21. Dragieva I, Stoeva S, Stoimenov P, Pavlikianov E, Klabunde K (1999) Complex formation in solutions for chemical synthesis of nanoscaled particles. Nanostruct Mater 12: 267.

22. Sondi I, Sondi BS (2004) Silver nanoparticles as antimicrobial agent: a case study on E.coli as model for gram negative bacteria. Jcolloid \& interface science 275 : $177-182$

23. Singh K, Panghal M, Kadyan S, Chaudhary U, Yadav JP (2014) Antibacteria Activity of Synthesized Silver Nanoparticles from Tinospora cordifolia agains Multi Drug Resistant Strains of Pseudomonas aeruginosa Isolated from Burn Patients. J Nanomed Nanotechnol 5: 192. 